\title{
Pengabdian Ke Masyarakat Dalam Penerapan Teknologi PTT Padi Di Kabupaten Sarolangun Provinsi Jambi
}

\author{
Suharyon \\ Balai Pengkajian Teknologi Pertanian (BPTP) Jambi \\ Email author: suharyonhariyon@mail.com
}

\begin{abstract}
ABSTRAK
Pengkajian Proses Komunikasi Dalam Penerapan Teknologi PTT (Pengelolaan Tanaman Terpadu) Padi Di Tingkat masyarakat tani Di Kecamatan Sarolangun adalah sebagai berikut : Proses komunikasi yang terjadi dalam penerapan teknologi PTT terjadi dalam 3 aktifitas yang terjadi yaitu ceramah, diskusi, dan praktek. Dalam proses komunikasi tersebut terdapat 2 model komunikasi yaitu secara linear atau satu arah pada sesi ceramah dan praktek dan dua arah/multi arah pada sesi diskusi dan pertemuan dengan masyarakat tani. Sementara tingkat penerapan 10 komponen teknologi PTT masih rendah dengan persentase 45,6\% untuk tanaman padi sawah dan 37,5\% untuk tanaman padi ladang, komunikasi yang berlangsung dalam penerapan teknologi PTT tidak efektif. Proses komunikasi yang efektif dalam penerapan teknologi PTT padi ditingkat masyarakat tani, apabila teknologi disampaikan secara langsung dilapangan baik teori maupun demontrasi.
\end{abstract}

Kata kunci : Pengabdian, Masyarakat tani, Teknologi PTT, Kabupaten Sarolangun

\section{PENDAHULUAN}

Sektor pertanian merupakan salah satu sektor yang penting dalam pembangunan perekonomian di Indonesia yang mayoritas penduduknya berusaha di bidang pertanian serta ditunjang oleh kondisi tanah, iklim, dan sumberdaya pendukung lain yang memadai untuk bercocok tanam. Menurut Arifin (2005), sektor pertanian merupakan pengganda pendapatan yang paling efektif dalam pengentasan masyarakat dari kemiskinan serta perbaikan taraf hidup dan kesejahteraan masyarakat.Tujuan dari pembangunan pertanian adalah untuk meningkatkan kesejahteraan petani dan keluarganya serta memberikan manfaat terhadap pembangunan di Indonesia. Dalam meningkatkan kesejahteraan petani tersebut, pembangunan pertanian harus berfokus kepada peningkatan produksi.

Pengelolaan Tanaman Terpadu (PTT) merupakan suatu upaya untuk meningkatkan produksi dan pendapatan masyarakat tani melalui penerapan teknologi yang sesuai dengan kondisi petani dan sumberdaya lingkungan setempat. PTT dilakukan secara sinergis yaitu masing-masing komponen teknologi saling menunjang dan berwawasan lingkungan sehingga usahataninya menjadi efisien, berproduksi tinggi dan berkelanjutan (BBP2TP, 2008: 1).

Proses diseminasi teknologi PTT dilakukan melalui kegiatan pelatihan PTT bagi penyuluh dan kegiatan Sekolah Lapang PTT (SL-PTT). Istilah diseminasi disini ialah proses penyebaran inovasi teknologi PTT yang direncanakan, diarahkan dan dikelola. Pelatihan PTT bagi penyuluh dilakukan dengan memberikan materi kepada penyuluh terkait 10 komponen teknologi PTT oleh narasumber dalam meningkatkan pengetahuan dan keterampilan penyuluh dalam menyampaikan informasi PTT kepada masyarakat tani. Dalam kegiatan Sekolah Lapang PTT yaitu Sekolah yang seluruh proses belajar-mengajarnya dilakukan di lapangan. Hamparan sawah milik petani peserta program PTT penerapan PTT disebut hamparan SL-PTT, sedangkan hamparan sawah tempat praktek sekolah lapang disebut laboratorium lapang (LL). SL-PTT tidak terkait dengan ruang kelas melainkan petani melakukan pertemuan dalam kegiatan belajar di saung dan tempat-tempat lain yang berdekatan dengan lahan belajar. (Deptan, 2008).

Proses diseminasi teknologi PTT kepada petani mengharuskan adanya komunikasi antara penyuluh dengan petani. Menurut Liliweri (2011: 64), inti dari komunikasi ke 
masyarakat adalah proses kegiatan yang berfungsi untuk menghubungkan pengirim dan penerima pesan melalui ruang dan waktu, sehingga komunikasi itu menjembatani antara komunikator dan komunikan untuk saling bertukar informasi agar terciptanya suatu kesamaan makna dari pesan tersebut.

Proses komunikasi melibatkan pelaku komunikasi, diantaranya penyuluh, petani, Kepala Balai Penyuluhan Pertanian Perikanan dan Kehutanan (BP3K). Penyuluh dalam bahasa komunikasi disebut sebagai komunikator yang menyampaikan informasi, petani sebagai penerima informasi disebut sebagai komunikan. Informasi disampaikan melalui dialog antara penyuluh kepada petani disebut message. Menurut Liliweri (2011: 411) dialog adalah proses untuk menciptakan kebersamaan makna yang tumbuh dan mengalir melalui kelompok.

\section{METODE PELAKSANAAN}

Metode yang digunakan adalah metode studi kasus. Metode studi kasus adalah pengkajian tentang status subjek yang berkenaan dengan suatu fase spesifik atau khas dari keseluruhan personalitas. Subjek pengkajian dapat saja individu, kelompok, lembaga, maupun masyarakat. Tujuan studi kasus adalah untuk memberikan gambaran secara mendetail tentang latar belakang, sifat-sifat serta karakter-karakter yang khas dari kasus, ataupun status individu, yang kemudian dari sifat-sifat khas di atas akan jadikan suatu hal yang bersifat umum Nazir, (2009).

\section{HASIL DAN PEMBAHASAN}

\subsection{Efektifitas komunikasi}

Untuk penentuan kelompok tani diambil dari kelompok tani binaan penyuluh yang berada di Desa Aur Gading dan Desa Lidung yang menerima program PTT dan telah mengikuti kegiatan SL-PTT. Dalam pengambilan responden petani tersebut dipilih ketua, dan 8 anggota dari kelompok tani tersebut yang diambil secara proposional random sampling (acak) untuk dijadikan sebagai responden.

Tabel 1. Daftar Responden (Petani) Binaan Penyuluh Pertanian (PPL)

\begin{tabular}{|c|c|c|c|c|c|}
\hline No & Desa & Responden & $\begin{array}{l}\text { Kelompok tani } \\
\text { Binaan }\end{array}$ & $\begin{array}{l}\text { Jumlah anggota Kelompok } \\
\text { Tani }\end{array}$ & Sampel \\
\hline \multirow[t]{2}{*}{1.} & Aur Gading & $\begin{array}{l}\text { Ketua, dan Anggota } \\
\text { kelompok tani }\end{array}$ & $\begin{array}{l}\text { Kelompok Tani } \\
\text { Pemancar (Padi } \\
\text { Sawah) }\end{array}$ & 14 & 8 \\
\hline & & & $\begin{array}{l}\text { Kelompok Tani } \\
\text { Rantau Bayur (Padi } \\
\text { Ladang) }\end{array}$ & 14 & 8 \\
\hline \multirow[t]{5}{*}{2.} & Lidung & $\begin{array}{l}\text { Ketua, dan Anggota } \\
\text { kelompok tani }\end{array}$ & $\begin{array}{l}\text { Kelompok Tani } \\
\text { Harapan Maju (Padi } \\
\text { Sawah) }\end{array}$ & 14 & 8 \\
\hline & & & $\begin{array}{l}\text { Kelompok Tani } \\
\text { Danau Biaro (Padi } \\
\text { Ladang) }\end{array}$ & 14 & 8 \\
\hline & & $\begin{array}{l}\text { Penyuluh Desa Aur } \\
\text { Gading }\end{array}$ & & 1 & \\
\hline & & $\begin{array}{l}\text { Penyuluh Desa } \\
\text { Lidung }\end{array}$ & & 1 & \\
\hline & & $\begin{array}{l}\text { Kepala Balai BP3K } \\
\text { Kecamatan } \\
\text { Sarolangun }\end{array}$ & 1 & & \\
\hline
\end{tabular}


(Informan Kunci)

$\begin{array}{lll}\text { Total } & 59 & 32\end{array}$

Sumber : Suharyon, 2017

Untuk mencapai tujuan yang diharapkan, maka data yang terkumpul akan dianalisis secara deskriptif kualitatif, baik data primer maupun data sekunder yang disesuaikan dengan data yang tersedia. Selanjutnya akan dilihat respon yang diberikan oleh petani/komunikan terhadap penyampain informasi, untuk menilai respon atau umpan balik dari hasil proses komunikasi yang terjadi dalam proses komunikasi antara penyuluh dengan $\mathrm{r}$ arakat tani dalam penerapan teknologi PTT digunakan 3 kategori jawaban (Mengerti, kuı aıg mengerti dan tidak mengerti).

\subsection{Proses Komunikasi Dalam Penerapan Teknologi PTT Di Tingkat Masyarakat tani}

Dalam mendeskripsikan proses komunikasi yang terjadi antara penyuluh dengan petani, sesuai dengan model komunikasi Lasswell yaitu :

1) Pelaku komunikasi merupakan orang-orang yang ikut serta dalam proses komunikasi,

2) Pesan yaitu materi yang disampaikan berupa pesan/informasi kepada pelaku komunikasi

3) Media yaitu alat bantu/bahan yang digunakan dalam menyampaikan pesan/informasi.

4) Feedback adalah respon/umpan balik yang diberikan oleh penerima terhadap pesan/informasi yang dikirimkan oleh pengirim.

Pelaku komunikasi disini ialah penyuluh "FT" sebagai komunikator dan petani sebagai komunikan. Penyuluh sebagai komunikator menyampaikan informasi 10 komponen Teknologi PTT kepada petani. Dalam penyampaian informasi kepada petani penyuluh menyampaikan informasi tersebut secara ceramah. Ceramah yang dilakukan penyuluh "FT", terlebih dahulu penyuluh dan kelompok tani berkumpul di saung tani, penyuluh berdiri dan petani duduk berbaris menghadap penyuluh sambil mendengarkan informasi yang disampaikan penyuluh mengenai 10 komponen Teknologi PTT dengan menggunakan media peta singkap, leaflet, poster, tapi penyuluh lebih sering menggunakan peta singkap yaitu dengan menggunakan kalender bekas yang digambar oleh penyuluh. Penyampaian informasi tersebut dilakukan dengan membalik-balik peta singkap tersebut yang telah diberi gambar oleh penyuluh. Sebagaimana salah anggota kelompok tani Pemancar menjelaskan bahwa pada saat penyuluh ceramah penyuluh menyampaikan informasi dengan menggunakan peta singkap yang ada gambar terkait masalah petani dalam melakukan usahatani padi.

Pesan atau informasi yang disampaikan penyuluh "FT" pada kelompok tani Pemancar dan Rantau Bayur berbeda, dimana pada saat proses komunikasi yang terjadi, penyuluh menyampaikan informasi kepada kelompok tani Pemancar dengan memberikan materi mengenai penggunaan Varietas unggul baru (VUB), penyuluh menjelaskan bahwa penggunaan VUB dapat menjamin pertumbuhan tanaman padi yang baik dengan hasil dan kualitas yang baik. Penggunaan VUB lebih spesfik kepada kondisi wilayah. Sehingga dalam penggunaan VUB dapat disesuaikan dengan potensi daerah yang berada di Kecamatan Sarolangin. Penyuluh juga menyampaiakan VUB yang digunakan untuk tanaman padi sawah ialah varietas Inpari disini penyuluh menjelasakan apa keuntungan dari penggunaan varietas Inpari, rasa dan aroma dari varietas Inpari. Sementara petani biasanya menanam dengan varietas lokal yaitu IR 42 . 
Penggunaan media penyampaian informasi 10 komponen teknologi PTT kepada masyarakat tani seperti yang dijelaskan sebelumnya bahwa penyuluh lebih sering menggunakan media peta singkap dalam memberikan informasi kepada petani. Dalam penggunaan media tersebut penyuluh lebih menekankan kepada gambar-gambar percontohan dalam penyampaian materi kepada petani, dikarenakan petani lebih gampang memahami dan mengerti dengan adanya gambar pada media tersebut. Media yang digunakan dalam penyampaian informasi untuk kelompok tani Pemancar dan Rantau Bayur sama. Pada saat materi padi sawah penyuluh menggunakan peta singkap dan pada saat materi padi ladang penyuluh menggunakan media peta singkap sesekali menggunakan poster ataupun leaflet. Adapun penggunaan media yang digunakan penyuluh terlihat pada tabel berikut :

Tabel 2. Media yang digunakan dalam penyampaian informasi pada pertemuan Kelompok tani

\begin{tabular}{|c|c|c|c|}
\hline No & Komponen teknologi & $\begin{array}{l}\text { Media yang digunakan } \\
\text { dalam penyampaian } \\
\text { informasi }\end{array}$ & $\begin{array}{l}\text { Jenis media sesuai dengan } \\
\text { komponen teknologi }\end{array}$ \\
\hline 1 & Varietas unggul & $\begin{array}{l}\text { Peta singkap, gambar/leaflet, } \\
\text { in focus }\end{array}$ & $\begin{array}{l}\text { Demplot, temu lapang, } \\
\text { kunjungan lapang }\end{array}$ \\
\hline 2 & Bibit Muda $(<21 \mathrm{HSS})$ & $\begin{array}{l}\text { Peta singkap, gambar/leaflet, } \\
\text { in focus }\end{array}$ & Demplot, temu lapang \\
\hline 3 & $\begin{array}{l}\text { Jumlah bibit batang } \\
\text { perlobang (1-3) }\end{array}$ & $\begin{array}{l}\text { Peta singkap, gambar/leaflet, } \\
\text { in focus }\end{array}$ & Temu lapang \\
\hline 4 & $\begin{array}{l}\text { Sistem tanam } \quad \text { jajar } \\
\text { legowo }(2: 1,4: 1)\end{array}$ & $\begin{array}{l}\text { Peta singkap, gambar, in } \\
\text { focus }\end{array}$ & Demplot, temu lapang \\
\hline 5 & $\begin{array}{l}\text { Pemupukan } \\
\text { berdasarkan BWD }\end{array}$ & $\begin{array}{l}\text { Peta singkap, gambar/leaflet, } \\
\text { in focus }\end{array}$ & Demplot, temu lapang \\
\hline 6 & $\begin{array}{ll}\text { Pumupukan } & P \text { dan } \mathrm{K} \\
\text { berdasarkan } & \text { status hara } \\
\text { tanah } & \end{array}$ & $\begin{array}{l}\text { Peta singkap, gambar/leaflet, } \\
\text { in focus }\end{array}$ & Demplot, temu lapang \\
\hline 7 & Bahan organik & $\begin{array}{l}\text { Peta singkap, gambar/leaflet, } \\
\text { in focus }\end{array}$ & Demplot, temu lapang \\
\hline 8 & Pengairan berselang & $\begin{array}{l}\text { Peta singkap, gambar/leaflet, } \\
\text { in focus }\end{array}$ & Temu lapang, juknis \\
\hline 9 & $\begin{array}{l}\text { Pengendalian hama dan } \\
\text { penyakit secara terpadu }\end{array}$ & $\begin{array}{l}\text { Peta singkap, gambar/leaflet, } \\
\text { in focus }\end{array}$ & Temu lapang, kunjungan lapang \\
\hline 10 & Panen beregu & $\begin{array}{l}\text { Peta singkap, gambar/leaflet, } \\
\text { in focus }\end{array}$ & Kunjungan lapang \\
\hline
\end{tabular}

Sumber : Suharyon, 2017

Proses penyampaian informasi kepada petani, berdasarkan pengamatan dan wawancara dilapangan bahwa media yang digunakan pada saat pertemuan di saung tani disampaikan secara satu arah pada saat ceramah dalam proses komunikasi yang berlangsung di dalam kelompok tani, seperti penggunaan media leaflet, peta singkap, dan poster.

Adapun respon/umpan balik yang diberikan petani pada saat pertemuan kelompok tani padi sawah dan padi ladang terlihat pada tabel berikut : 
Tabel 3. Respon petani terhadap materi dan demonstrasi Varietas Unggul Baru pada tanaman padi sawah Desa Aur Gading

\begin{tabular}{lll}
\hline \multirow{2}{*}{ No } & Respon & \multicolumn{2}{c}{ Jumlah Petani } \\
\cline { 3 - 3 } & Materi & Demonstrasi \\
\hline \multirow{2}{*}{ 1Mengerti } & $2(25 \%)$ & $1(12,5 \%)$ \\
2Kurang Mengerti & $3(37,5 \%)$ & $4(50 \%)$ \\
3Tidak Mengerti & $3(37,5 \%)$ & $3(37,5 \%)$ \\
\hline
\end{tabular}

Sumber :Suharyon, 2017

Dari Tabel 3 dapat dijelaskan bahwa pada saat pertemuan kelompok tani Pemancar, petani yang tidak mengerti lebih banyak $37,5 \%$ di bandingkan dengan petani yang mengerti $25 \%$, dikarenakan pada saat penyampaian materi respon yang diberikan petani sangatlah beragam sehingga tidak semua mengerti dengan apa yang telah disampaikan oleh penyuluh baik pada saat penyuluh ceramah maupun pada saat diskusi, sementara pada saat Demonstrasi dari persentase terlihat bahwa penggunaan VUB agak rumit bagi petani dengan persentase $50 \%$, dimana penggunaan Teknologi VUB petani tidak terbiasa yang dilihat dari rasa dan aroma beras yang dihasilkan tidak biasa di konsumsi petani tersebut.

Adapun respon/umpan balik yang diberikan petani pada saat pertemuan kelompok tani padi sawah dan padi ladang terlihat pada tabel berikut :

Tabel 4. Respon petani terhadap materi dan demonstrasi pengolahan tanah pada tanaman padi sawah Desa Lidung

\begin{tabular}{llll}
\multirow{2}{*}{ No } & Respon & \multicolumn{2}{l}{ Jumlah Petani } \\
\cline { 3 - 4 } & & Materi & Demonstrasi \\
\hline 1 & Mengerti & $1(12,5 \%)$ & $1(12 \%)$ \\
2 & Kurang Mengerti & $3(37,5 \%)$ & $4(50 \%)$ \\
3 & Tidak Mengerti & $4(50 \%)$ & $3(37,5 \%)$ \\
\hline
\end{tabular}

Dari Tabel di atas dapat dijelaskan bahwa pada saat pertemuan kelompok tani Harapan Maju pada saat penyuluh memberikan materi secara ceramah dan diskusi dengan petani kebanyakan petani tidak mengerti dilihat dari persentase petani yang tidak mengerti $50 \%$, sementara pada saat praktek percontohan dalam mempraktekan dari apa yang disampaikan penyuluh $50 \%$ petani agak rumit mempraktekanya di lahan. Sehingga pada saat pertemuan dalam penyampaian materi kepada petani akan berpengaruh pada saat petani praktek dilapangan.

Lebih memahami dari Teknologi tersebut dengan persentase $37,5 \%$ petani pada saat mempraktekan Teknologi sederhana. Dikarenakan pada saat praktek petani lebih fokus karena berhubungan langusung kepada lahan petani sendiri. 


\section{KESIMPULAN}

Kesimpulan dari pengkajian Proses Komunikasi Dalam Penerapan Teknologi PTT (Pengelolaan Tanaman Terpadu) Padi Di Tingkat Petani Di Kecamatan Sarolangun adalah sebagai berikut :

1. Proses komunikasi yang terjadi dalam penerapan teknologi PTT terjadi dalam 3 aktifitas yang terjadi yaitu ceramah, diskusi, dan praktek. Dalam proses komunikasi tersebut terdapat 2 model komunikasi yaitu secara linear atau satu arah pada sesi ceramah dan praktek dan dua arah/multi arah pada sesi diskusi dan pertemuan dengan petani individu. Sementara tingkat penerapan 10 komponen teknologi PTT masih rendah dengan persentase $45,6 \%$ untuk tanaman padi sawah dan $37,5 \%$ untuk tanaman padi ladang, komunikasi yang berlangsung dalam penerapan teknologi PTT tidak efektif.

2. Proses komunikasi yang efektif dalam penerapan teknologi PTT padi ditingkat petani, apabila teknologi disampaikan secara langsung dilapangan baik teori maupun demontrasi.

\section{DAFTAR PUSTAKA}

Badan Penyuluhan Dan Pengembangan Pertanian. 2012. Pedoman Pelaksanaan Pengawalan Dan Pendampingan Penyuluhan Pertanian Dalam Mendukung P2BN Di Lokasi SL-PTT Dan Demfarm SL Agribisnis Padi. Kementerian Pertanian.

Badan Penelitian Dan Pengembangan Pertanian. 2014. Panduan Pendampingan Pengelolaan Tanaman Terpadu. Kementerian Pertanian.

Balai Besar Pengkajian Dan Pengembangan Teknologi Pertanian. 2007. Inovasi Teknologi Untuk Meningkatkan Produktivitas Tanaman Padi. Badan Penelitian Dan Pengembangan Pertanian, Departemen Pertanian.

Balai Besar Pengkajian Dan Pengembangan Teknologi Pertanian. 2008. Teknologi Budidaya Padi. BBP2TP. Badan Litbang, Departemen Pertanian.

Bungin, Burhan. 2006. Sosiologi Komunikasi. Jakarta: Kencana

Daniel, Moeher. 2002. Pengantar Ekonomi Pertanian. Jakarta: PT Raja Grafindo Persada.

DI-UPTB Balai Penyuluhan Pertanian, Perikanan, Kehutanan (BP3K). Kecamatan Sarolangun. Tahun 2015.

Kementerian Pertanian Direktorat Jendral Tanaman Pangan. 2011. Peningkatan Produksi Beras Nasional (P2BN) Menuju Surplus Beras 10 Juta Ton. Departemen Pertanian.

Liliweri, Alo. 2011. Komunikasi Serba Ada Serba Makna. Jakarta: Prenada Media Group.

Peraturan Menteri Pertanian. 2011. Tata Hubungan Kerja Antar Kelembagaan Teknis, Penelitian, Dan Pengembangan, Dan Penyuluhan Pertanian Dalam Mendukung Peningkatan Produksi Beras Nasional (P2BN). NOMOR 45/Pementan/OT. 140/8/2011.

Pedoman Teknis Sekolah Lapangan Pengelolaan Tanaman Terpadu (SL-PTT) Padi Dan Jagung. 2014. Kementerian Pertanian. 